\title{
Hyperglycaemia slows gastric emptying in Type 1 (insulin-dependent) diabetes mellitus
}

\author{
R.J.Fraser ${ }^{1}$, M.Horowitz ${ }^{1}$, A.F. Maddox ${ }^{1}$, P.E.Harding ${ }^{3}$, B. E. Chatterton ${ }^{4}$ and J.Dent ${ }^{2}$ \\ Departments of ${ }^{1}$ Medicine, ${ }^{2}$ Gastroenterology, ${ }^{3}$ Endocrinology and \\ ${ }^{4}$ Nuclear Medicine, Royal Adelaide Hospital, North Terrace, Adelaide, Australia
}

\begin{abstract}
Summary. In 10 patients with Type 1 (insulin-dependent) diabetes mellitus gastric emptying of a digestible solid and liquid meal was measured during euglycaemia (blood glucose concentration $4-8 \mathrm{mmol} / \mathrm{l}$ ) and during hyperglycaemia (blood glucose concentration 16-20 mmol/1). Gastric emptying was studied with a scintigraphic technique and blood glucose concentrations were stabilised using a modified glucose clamp. Patients were also evaluated for gastrointestinal symptoms, autonomic nerve function and glycaemic control. When compared to euglycaemia, the duration of the lag phase before any of the solid meal emptied from the stomach
\end{abstract}

( $p=0.032)$, the percentage of the solid meal remaining in the stomach at $100 \mathrm{~min}(p=0.032)$ and the $50 \%$ emptying time for the solid meal $(p=0.032)$ increased during hyperglycaemia. The $50 \%$ emptying time for the liquid meal ( $p=0.042$ ) was also prolonged during the period of hyperglycaemia. These results demonstrate that the rate of gastric emptying in Type 1 diabetes is affected by the blood glucose concentration.

Key words: Gastric emptying, stomach, hyperglycaemia, autonomic neuropathy.
Recent studies have demonstrated that approximately $50 \%$ of patients with diabetes mellitus have delayed gastric emptying [1-3]. Since the control of blood glucose concentrations in Type 1 (insulin-dependent) diabetes mellitus is dependent on how well the delivery of administered insulin is matched with the rate of nutrient absorption from the small intestine, abnormal gastric emptying may not only cause gastrointestinal symptoms, but also contribute to poor glycaemic control $[4,5]$. Diabetic gastroparesis has been traditionally thought to reflect irreversible autonomic nerve damage [5-7], but there is some evidence that gastric emptying is also modified by the blood glucose concentration $[1,3]$. Acute hyperglycaemia slows gastric emptying in normal subjects [8-10] and recent studies, in which blood glucose concentrations were monitored, but not made constant during a single measurement of gastric emptying, suggest that there is an inverse relationship between the blood glucose concentration and the rate of gastric emptying in Type 1 and Type 2 (non-insulin-dependent) diabetic patients $[1,3]$. In these latter studies it was unclear whether delay in gastric emptying was related to acute or chronic hyperglycaemia. We have now measured gastric emptying in patients with Type 1 diabetes during hyperglycaemia and euglycaemia and confirm that gastric emptying is slower at an increased blood glucose concentration.

\section{Subjects, materials and methods}

The studies were performed in 10 patients with Type 1 diabetes ( 7 male, 3 female), who were selected randomly from all the ambulant out-patients treated for Type 1 diabetes by two members (MH and $\mathrm{PH}$ ) of the Endocrine Unit of the Royal Adelaide Hospital. Clinical data on these patients are shown in Table 1. The median duration of known diabetes was 15 years (range 1-22). Patients were not included in the study if they were taking any medication other than insulin. The plasma creatinine concentration was within the normal range $(0.05-0.12 \mathrm{mmol} / \mathrm{l})$ in all of the patients. Smoking was prohibited on the day of any gastric emptying measurement. Written, informed consent was obtained in all cases and the study was approved by the Ethics Committee of the Royal Adelaide Hospital.

\section{Protocol}

In each diabetic patient gastric emptying was measured twice: during euglycaemia (venous blood glucose $4-8 \mathrm{mmol} / \mathrm{l}$ ) and during hyperglycaemia (blood glucose 16-20 mmol/l). The order of the two tests was randomized and they were separated by approximately one 
Table 1. Clinical features of the patients

\begin{tabular}{|c|c|c|c|c|c|c|c|c|c|c|c|}
\hline \multirow[t]{2}{*}{$\begin{array}{l}\text { Patient } \\
\text { No. }\end{array}$} & \multirow[t]{2}{*}{$\begin{array}{l}\text { Age } \\
\text { (years) }\end{array}$} & \multirow{2}{*}{$\begin{array}{l}\text { Duration } \\
\text { of diabetes } \\
\text { mellitus } \\
\text { (years) }\end{array}$} & \multirow[t]{2}{*}{ Sex } & \multirow[t]{2}{*}{ BMI } & \multirow[t]{2}{*}{$\mathrm{Hb}_{1 \mathrm{C}}$} & \multicolumn{3}{|c|}{$\begin{array}{l}\text { Autonomic nerve } \\
\text { function Tests }\end{array}$} & \multicolumn{3}{|c|}{$\begin{array}{l}\text { Upper gastrointestinal } \\
\text { Symptom score }\end{array}$} \\
\hline & & & & & & $\overline{\mathrm{DB}}$ & $\mathrm{L} / \mathrm{St}$ & $\mathrm{BP}^{\mathrm{b}}$ & "Gastric" & $\begin{array}{l}\text { "Oesoph- } \\
\text { ageal" }\end{array}$ & Total \\
\hline 1 & 41 & 17 & $M$ & 21.9 & 4.8 & 1 & 0 & 0 & 1 & 0 & 1 \\
\hline 2 & 47 & 17 & $\mathrm{~F}$ & 22.4 & 11.0 & 1 & 0 & 0 & 2 & 0 & 2 \\
\hline 3 & 43 & 7 & M & 33.0 & 10.5 & 1 & 0 & 0 & 1 & 2 & 3 \\
\hline 4 & 27 & 4 & $\mathrm{M}$ & 25.5 & 9.2 & 0 & 0 & 0 & 0 & 0 & 0 \\
\hline 7 & 54 & 15 & $M$ & 23.8 & 10.3 & 2 & 0 & 1 & 1 & 4 & 5 \\
\hline 8 & 43 & 22 & $\mathrm{~F}$ & 25.8 & 13.0 & 2 & 2 & 2 & 1 & 1 & 1 \\
\hline 9 & 37 & 12 & $\mathrm{M}$ & 27.5 & 12.8 & 2 & 2 & 0 & 5 & 0 & 5 \\
\hline 10 & 45 & 8 & $\mathrm{M}$ & 22.4 & 12.4 & 0 & 0 & 2 & 0 & 0 & 0 \\
\hline
\end{tabular}

$0=$ Normal; 1 = borderline; 2 = abnormal

${ }^{a} \mathrm{DB}=$ heart rate response to deep breathing; $\mathrm{L} / \mathrm{St}=$ lying/standing heart rate; ${ }^{\mathrm{b}} \mathrm{BP}=$ systolic blood pressure response to standing; ${ }^{c}$ "Gastric" symptoms: anorexia, nausea, early satiety, abdominal distention, vomiting, abdominal pain "oesophageal" symptoms: dysphagia, heartburn, acid regurgitation; 0 =none, 1 = mild, 2 =moderate, 3 = severe; the score represents the sum of individual symptoms

week. Venous blood glucose concentrations were maintained in either the euglycaemic, or the hyperglycaemic range with the use of a modified glucose clamp technique [11]. After entry into the study (and within two days of the first gastric emptying measurement) each subject had $\mathrm{HbA}_{\mathrm{IC}}$ measured, an evaluation of gastrointestinal symptoms with a questionnaire and an objective assessment of autonomic nerve function with cardiovascular reflex tests $[1,3,12-15]$. The $\mathrm{HbA}_{1 \mathrm{C}}$ results were expressed as a percentage; the range in normal subjects being $3.5-6.0 \%$ [1].

\section{Stabilization of blood glucose concentrations}

On the morning of each gastric emptying measurement an i.v. catheter was inserted into an antecubital vein at approximately 08.00 hours, after each subject had fasted from solids from 19.00 hours and liquids from 24.00 hours the previous day. Intravenous infusions of insulin (Actrapid human, CSL-Novo, Sydney, NSW, Australia) and/or glucose (10\% glucose in water) were then commenced via an infusion pump and subsequently adjusted, by frequent measurements of blood glucose, so that the venous blood glucose concentration was maintained either in the range $4-8 \mathrm{mmol} / \mathrm{l}$, or $16-20 \mathrm{mmol} / \mathrm{h}$ for at least $60 \mathrm{~min}$ before the commencement of, and during the gastric emptying measurement [11]. Blood was taken from a catheter placed in an antecubital vein of the contralateral $\mathrm{arm}$. In the total study period the rate of the insulin infusion varied from $0.5-8.0 \mathrm{U} / \mathrm{h}$ and the rate of glucose infusion varied from 0 $15 \mathrm{~g} / \mathrm{h}$. Measurements of blood glucose concentration were performed during each test with BM-Test-Glycemie 20-800 strips (Boehringer-Mannheim, Sydney, NSW, Australia) and a portable glucose meter (Reflolux 11M, Boehringer-Mannheim). Blood glucose measurements were also made subsequently on these venous samples with a hexokinase technique and these values are reported in the text.

\section{Measurement of gastric emptying}

Details of this double isotope test, which measures gastric emptying of solid and liquid meals simultaneously have been published [16, 17]. The solid meal was $100 \mathrm{~g}$ of cooked ground beef containing $1.0-1.5 \mathrm{mCi}$ of in vivo labelled ${ }^{99 \mathrm{~m}} \mathrm{Tc}$-sulphur colloid chicken liver [16]. The liquid meal consisted of $150 \mathrm{ml}$ of $10 \%$ dextrose in water labelled with $0.75-1 \mathrm{mCi}$ of ${ }^{115 \mathrm{~m} I n-D T P A}$ (diethylenetriamepentaacetic acid). The test was commenced at approximately 12.00 hours. Patients sat with the scintillation camera behind them and ate the solid meal over $5 \mathrm{~min}$, followed immediately by the dextrose drink. Each study was continued for at least $3 \mathrm{~h}$ after meal completion, which was taken as time zero.

Data were corrected for patient movernent, radionuclide decay, Compton scatter and gamma ray (tissue) attenuation using previously described methods $[16,17]$. A proximal stomach region-ofinterest was defined by the "reservoir" area seen in all subjects for at least the first few min after ingestion of the solid meal [17]. From the curves of solid and liquid gastric emptying (expressed as a percentage of the total meal remaining within the stomach vs time) several parameters were derived for subsequent analysis. For the solid meal these were: (1) the lag phase before any food left the stomach, (2) the amount of isotope remaining in the stomach at $100 \mathrm{~min}$ after meal completion, and (3) the time for $50 \%$ gastric emptying. In some patients with delayed gastric emptying the pattern of emptying was too irregular for accurate determination of a linear emtpying rate for the solid meal, and consequently this parameter was not used for statistical analysis. Intragastric distribution of the solid meal was evaluated by determining the time for $50 \%$ of the meal to leave the proximal stomach region and the amount which remained in the proximal stomach at 100 min $[13,16,17]$. Comparisons of liquid meal emptying were made with values for the amount remaining in the stomach at $5 \mathrm{~min}$ and the time for $50 \%$ emptying $[13,16]$.

In our laboratory a "normal range" for gastric emptying has been obtained with an identical test meal in 22 normal volunteers (14 male, 8 female), median age 33 years (range 21-62) median body mass index 23.0 (range 20.0-26.6) and median body weight $72 \mathrm{~kg}$ (range 57-89) who were non-smokers, on no medication and without evidence of gastrointestinal disease [1]. We have defined "delayed" gastric emptying as values more than two standard deviations above the mean in this group for either the amount of the solid meal remaining in the stomach at $100 \mathrm{~min}(\geqslant 61 \%)$, or the $50 \%$ emptying time of the liquid meal $(\geqslant 31 \mathrm{~min})[1]$.

\section{Assessment of gastrointestinal symptoms}

Upper gastrointestinal symptoms were assessed by a standard questionnaire $[1,3,12,13]$. Anorexia, nausea, early satiety, upper abdominal discomfort or distention, vomiting, abdominal pain ("gastric" symptoms), dysphagia, heartburn and acid regurgitation ("oesophageal" symptoms) were scored according to the following scheme: $0=$ none, $1=$ mild (symptom could be ignored if the patient did not think about it), moderate (symptom could not be ignored, but did not influence daily activities), $3=$ severe (symptom influenced daily activities). The maximum possible total score was 18 for the "gastric" symptoms and was 9 for the "oesophageal" symp- 


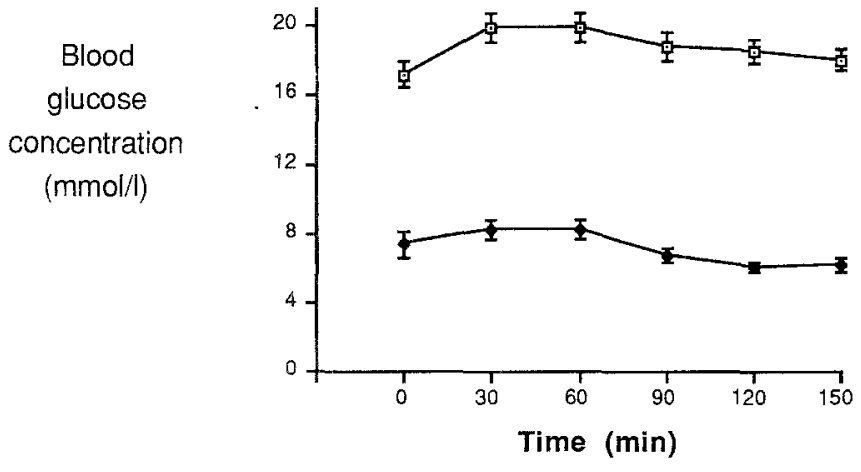

Fig. 1. Mean blood glucose concentrations ( \pm S. E.M.) at $30 \mathrm{~min}$ intervals following ingestion of the test meal during euglycaemia (-) and hyperglycaemia (-๑-)

toms. The number of bowel actions each week, the consistency of bowel actions and the presence or absence of nocturnal diarrhoea and faecal incontinence were also noted. The patient was considered to suffer from constipation if less than three spontaneous bowel actions occurred each week.

\section{Assessment of autonomic neuropathy, peripheral neuropathy and retinopathy}

Autonomic nerve function was assessed by standard cardiovascular reflex tests. Parasympathetic function was evaluated by the heart rate variation (R-R interval) during deep breathing and the immediate heart rate response to standing (" $30: 15$ " ratio). Sympathetic function was assessed by the fall in systolic blood pressure in response to standing. The result of each of these tests was scored as $0=$ normal $1=$ borderline, or $2=$ abnormal (for a maximum possible score of 6), according to criteria outlined by Ewing and Clarke [14]. A total score of $\geqslant 3$ was taken to indicate definite autonomic nerve damage $[1,3,13]$.

Retinopathy was graded as none, background or proliferative on the basis of a recent ophthalmological assessment, which often included fluoroscein angiography. Peripheral neuropathy was diagnosed clinically when absent ankle reflexes were associated with either sensory or motor changes.

\section{Statistical analysis}

Data were evaluated using the Wilcoxon rank-sum test (paired data) and linear regression analysis. Data are shown as median values and ranges unless otherwise stated. A $p$-value of $<0.05$ was considered significant in all analyses. As it was postulated that hyperglycaemia would slow gastric emptying, one way tests of significance were applied to the analysis of the gastric emptying data.

\section{Results}

\section{Gastrointestinal symptoms and diabetic complications}

There was considerable variation in gastrointestinal symptoms between patients. The median score for "gastric" symptoms was 1 (range 0-5) and the median score for "oesophageal" symptoms was $0(0-4)$. Of the other gastrointestinal symptoms one patient suffered from constipation, none had nocturnal diarrhoea, and none had faecal incontinence. Three of the patients had definite evidence of autonomic neuropathy (total score $\geqslant 3$ ) and seven had a score of 1 or more (Table 1 ). Three patients had peripheral neuropathy. Four patients had no retinopathy, four patients had background retinopathy and two patients had proliferative retinopathy.

\section{Glycosylated haemoglobin concentrations}

The $\mathrm{HbA}_{1 \mathrm{c}}$ concentrations are shown in Table 1. One patient was in the range for normal, no patient was in the range $6.1-9.0 \%$, six patients were in the range $9.1-12.0 \%$ and three patients had values $>12.0 \%$.

\section{Glucose and insulin values during the study}

In the first $2 \mathrm{~h}$ after the commencement of the gastric emptying measurement there was no significant difference $(p=0.30)$ in the median rate of insulin infusion between the two tests $1.6 \mathrm{U} / \mathrm{h}(0.4-11.5)$ during the hyperglycaemic test and $2.0 \mathrm{U} / \mathrm{h}(1.4-4.4)$ during the euglycaemic test. There was a non-significant trend $(p=0.16)$ for the median rate of glucose infusion to be higher in the hyperglycaemic test $(4.7 \mathrm{~g} / \mathrm{h}(1.4-12.1))$ than during the euglycaemic test $(3.4 \mathrm{~g} / \mathrm{h}(0.3-8.6))$. The mean blood glucose concentrations are summarised in Figure 1.

\section{Gastric emptying}

Solid emptying. 1. Total stomach emptying: in all subjects solid emptying was slower than liquid emptying and was characterized by an initial lag phase followed by an emptying phase. Gastric emptying of the solid meal was slower during hyperglycaemia, compared to euglycaemia in nine of the ten patients. There was prolongation of the lag phase (56 $\min (27-93)$ vs $46 \min (22-78), p=0.032)$ and the $50 \%$ emptying time (141 $\mathrm{min}(86-220)$ vs $124 \mathrm{~min}$ $(80-150), p=0.032)$ (Fig.2). The percentage retention of the meal at 100 min was also increased during hyperglycaemia (71\% (36-97) vs $61 \%(37-75) p=0.032)$. Total stomach emptying of the solid meal at 100 min was within the delayed range in five of the diabetic patients during euglycaemia and in seven of the patients during hyperglycaemia.

2. Intragastric distribution: when compared to euglycaemia there were non-significant trends for prolongation of the time for $50 \%$ of the meal to leave the proximal stomach and the amount of the meal remaining in the proximal stomach at $100 \mathrm{~min}$ during hyperglycaemia (42 $\mathrm{min}$ (9-72) vs $28 \min (4-65) p=0.097)$ and $19 \%(6-37)$ vs $15 \%$ (4-36), $p=0.14$ respectively). The percentage of the meal remaining in the proximal stomach at 100 min correlated directly with both the duration of the lag phase $(r=0.64$, $p<0.003$ ) and the amount of the meal remaining in the total stomach at $100 \mathrm{~min}(r=0.64, p<0.003)$.

Liquid emptying. In all but one of the patients the emptying curve for the liquid meal was non-linear with a slope 


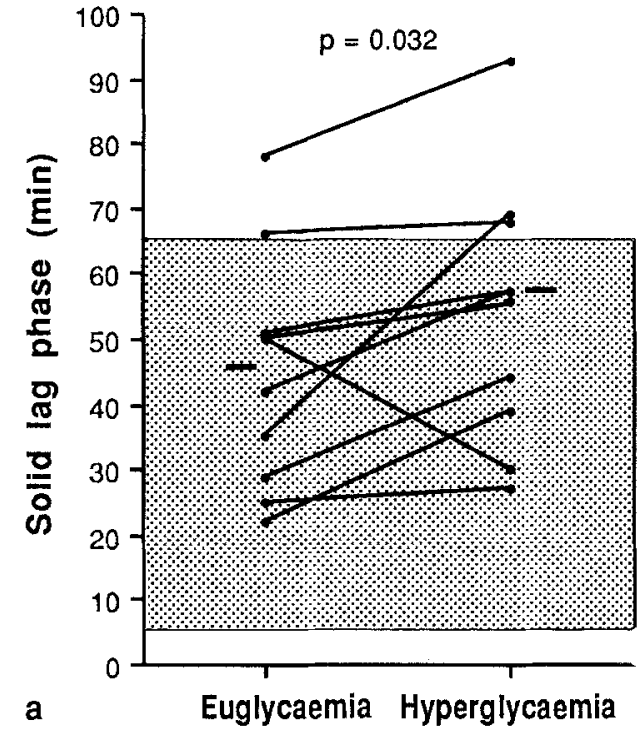

that decreased with time and approximated a monoexponential pattern. In patient six there was the surprising observation of a lag phase of $29 \mathrm{~min}$ in the euglycaemic study (the lag phase for the liquid meal was less than $8 \mathrm{~min}$ in all of the other studies). In nine of the ten patients the $50 \%$ emptying time of the liquid meal was slower during hyperglycaemia than with euglycaemia (41 $\mathrm{min}(26-56)$ vs 35 min (19-61), $p=0.042$ ) (Fig. 3). The nine out of ten subjects who showed slower solid emptying during hyperglycaemia were not the same as those who had slowed liquid emptying. There was a non-significant trend for greater retention of the liquid meal at $5 \mathrm{~min}$ during hyperglycaemia (99 (88-100) vs $95(82-100), p=0.081)$. The $50 \%$ emptying time for the liquid meal was delayed in six patients during euglycaemia and in 8 patients during hyperglycaemia.

There was no significant relationship between either solid or liquid gastric emptying (on the euglycaemic or

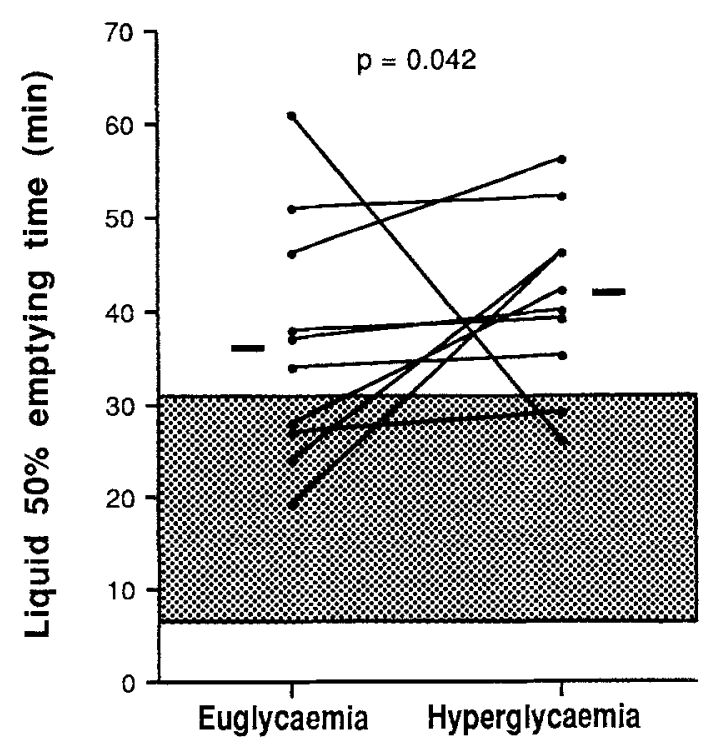

Fig.3. Individual values for liquid gastric emptying expressed as the $50 \%$ emptying time, during euglycaemia (left) and hyperglycaemia (right). The range for the liquid $50 \%$ emptying time (mean $\pm 2 \mathrm{SD}$ ) obtained in the 22 control subjects (1) is shown in the shaded area hyperglycaemic test) and autonomic nerve function, the duration of diabetes, plasma creatinine, or gastrointestinal symptoms.

\section{Discussion}

We have shown that gastric emptying in patients with Type 1 diabetes is influenced by the blood glucose concentration, indicating that diabetic gastroparesis may result from poor glycaemic control. This observation is consistent with results of our previous studies in patients with Type 1 and 2 diabetes $[1,3]$. Delayed gastric emptying of liquid barium sulphate has been reported in patients with poor glycaemic control, but without evidence of autonomic neuropathy [18]. Wright et al. [19] did not find any relationship between blood glucose and gastric emptying, but they studied only ten patients who all had autonomic neuropathy. Variations in blood glucose concentrations may account for the poor reproducibility of gastric emptying in Type 2 diabetic patients [20] and the contradictory results regarding the prevalence of abnormal gastric emptying, particularly of liquids, in Type 1 patients $[1-3,19,21,22]$. Although marked changes in gastric emptying were observed in some patients, the magnitude of the difference between hyperglycaemia and euglycaemia was variable, and the median change was relatively modest. These observations are consistent with the response of diabetic patients to gastrokinetic drugs $[12,13]$.

The mechanism(s) responsible for the inhibitory action of hyperglycaemia on gastric emptying is not known. Proximal gastric tone, antral motility and pyloric and duodenal resistance are probably all important in the regulation of gastric emptying [23,24]. In normal subjects induced hyperglycaemia slows gastric emptying of nutrient-containing liquid meals [8-10] and, during fasting, decreases antral pressure waves [25]. Recently, we have demonstrated that hyperglycaemia stimulates pyloric motility in normal subjects [26]. Hyperglycaemia may therefore account, at least in part, for the results of manometric 
studies in Type 1 patients with symptomatic gastroparesis, which have shown diminished antral pressure waves, absence of antral phase 3 motor activity and an increased number of pyloric pressure waves $[6,7,27,28]$. In these studies blood glucose concentrations were apparently not monitored. Because of these effects on motility, hyperglycaemia may also contribute to delayed gastric emptying of non-digestible solid particles in diabetic gastroparesis [29]. Hyperglycaemia may suppress vagal nerve activity [30] and be an important factor in the aetiology of autonomic nerve dysfunction [31]. Alterations in the secretion of gastrointestinal hormones (such as motilin, somatostatin, glucagon and gastric inhibitory polypeptide) may also be important $[10,25,32]$. A previous study [33] indicates that the changes in gastric motility are not due to direct effects of insulin.

Our results have several important implications. It is apparent that the definition of diabetic gastroparesis must take into account the blood glucose concentrations during the performance of the gastric emptying measurement. Adequate control of blood glucose is also important in the assessment of the effects of pharmacological agents on gastric motility, or gastric emptying in patients with diabetes. The results also suggest that gastric emptying may be a hitherto underemphasised contributor to variations in glycaemic control in diabetes. Changes in gastric emptying resulting from variations in blood glucose concentration may contribute to upper gastrointestinal symptoms and poor glycaemic control. The latter hypothesis is supported by a recent study in normal subjects [35] which demonstrated that hyperglycaemia delays the absorption of the sulphonylurea drug, glipizide, presumably by slowing gastric emptying. Conversely it remains probable, but unproven, that delayed gastric emptying due to irreversible autonomic nerve damage may also contribute to poor blood glucose controlby causing discrepancies between the onset of insulin action and the release of nutrients into the intestine. The effects of changes in blood glucose concentrations on the function of other regions of the gastrointestinal tract also warrant evaluation. Our results provide a further rationale to improve, and avoid major fluctuations in blood glucose levels in diabetic patients.

Acknowledgements. The study was supported by grants from the National Health and Medical Research Council of Australia and the Rebecca L. Cooper Medical Research Foundation. We wish to thank Mrs. M. Marucci for typing this manuscript and Ms. J. Wishart for performing some of the statistical analyses. This study was presented at the 90th annual meeting of the American Gastroenterological Association held in Washington D.C., May 13-19, 1989 and published in abstract form (Gastroenterology 1989; $96:$ A158).

\section{References}

1. Horowitz M, Harding PE, Maddox A, Maddern GJ, Collins PJ, Chatterton BE, Wishart J, Shearman DJC (1986) Gastric and oesophageal emptying in insulin-dependent diabetes mellitus. J Gastroent Hepatol 1: 97-113

2. Keshavarzian A, Iber FL, Vaeth J (1987) Gastric emptying in patients with insulin-requiring diabetes mellitus. Am J Gastroent $82: 29-35$
3. Horowitz M, Harding PE, Maddox A, Wishart JM, Akkermans LMA, Chatterton BE, Shearman DJC (1989) Gastric and oesophageal emptying in patients with Type 2 (non-insulin-dependent) diabetes mellitus. Diabetologia 32: 151-159

4. Kassander $\mathrm{P}$ (1958) Asymptomatic gastric retention in diabetics (gastroparesis diabeticorum). Ann Intern Med 48: 797-812

5. Feldman M, Schiller LR (1983) Disorders of gastrointestinal motility associated with diabetes mellitus. Ann Intern Med 98: 378-384

6. Camilleri M, Malagelada J-R (1984) Abnormal intestinal motility in diabetics with the gastroparesis syndrome. Eur J Clin Invest $14: 420-427$

7. Malagelada J-R, Rees WDW, Mazzotta LJ, Go VLW (1980) Gastric motor abnormalities in diabetic and postvagotomy gastroparesis, effect of metoclopramide and bethanechol. Gastroenterology 78: 286-293

8. MacGregor IL, Gueller R, Watts HD, Meyer JH (1976) The effect of acute hyperglycaemia on gastric emptying in man. Gastroenterology 70: 190-196

9. Aylett $P$ (1962) Gastric emptying and change of blood glucose level as affected by glucagon and insulin. Clin Sci 22: 171-178

10. Morgan LM, Tredger JA, Hampton SM, French AP, Peake JC, Marks V (1988) The effect of dietary modification and hyperglycaemia on gastric emptying and gastric inhibitory polypeptide (GIP) secretion. Br J Nutr 60: 29-37

11. De Fronzo RA, Tobin JD, Andres R (1978) Glucose clamp technique: a method for quantifying insulin secretion and resistance. Am J Physiol 237: E214-223

12. Horowitz M, Harding PE, Chatterton BE, Collins PJ, Shearman DJC (1985) Acute and chronic effects of domperidone on gastric emptying in diabetic autonomic neuropathy. Dig Dis Sci 30: $1-9$

13. Horowitz M, Maddox A, Harding PE, Maddern GJ, Chatterton BE, Wishart J, Shearman DJC (1987) Effect of cisapride on gastric and esophageal emptying in insulin-dependent diabetes mellitus. Gastroenterology 92: 1899-1907

14. Ewing DJ, Clarke BF (1982) Diagnosis and management of diabetic autonomic neuropathy. Br Med J 285: 916-918

15. Jeppsson J, Jerntorp P, Sundkvist G, Englund H, Nylund V (1986) Measurement of hemoglobin Alc by a new liquid-chromatographic assay. Methodology, clinical utility and relation to glucose tolerance evaluated. Clin Chem 32: 1867-1872

16. Collins PJ, Horowitz M, Cook DJ, Harding PE, Shearman DJC (1983) Gastric emptying in normal subjects. A reproducible technique using a single scintillation camera and computer system. Gut 24: 1117-1125

17. Collins PJ, Horowitz M, Chatterton BE (1988) Proximal, distal and total stomach emptying of a digestible solid meal in normal subjects. Br J Radiol 61: 12-18

18. Soler NG (1980) Diabetic gastroparesis without autonomic neuropathy. Diabetes Care 3: 200-201

19. Wright RA, Clemente R, Wathen R (1985) Diabetic gastroparesis: an abnormality of gastric emptying of solids. Am J Med Sci 289: 240-242

20. Leatherdale BA, Green DJ, Harding LK, Griffin D, Bailey CJ (1982) Guar and gastric emptying in non-insulin dependent diabetes. Acta Diabet Lat 19:339-343

21. Campbell JW, Heading RC, Tothill P, Buist TAS, Ewing DJ, Clarke BF (1977) Gastric emptying in diabetic autonomic neuropathy. Gut 18: $462-467$

22. Loo FD, Palmer DW, Soergel KH, Kalbfleisch JH, Wood CM (1984) Gastric emptying in patients with diabetes mellitus. Gastroenterology 86: 485-494

23. Houghton LA, Read NW, Heddle R, Horowitz M, Collins PJ, Chatterton B, Dent J (1988) The relationship of the motor activity of the antrum, pylorus and duodenum to gastric emptying of a solid-liquid mixed meal. Gastroenterology 94: 12851291

24. Meyer JH (1987) Motility of the stomach and gastroduodenal junction. In: Johnson LR (ed) Physiology of the gastrointestinal tract, 2nd edn, vol 1. Raven, New York, pp 613-630 
25. Barnett JL, Owyang C (1988) Serum glucose concentration as a modulator of interdigestive gastric motility. Gastroenterology 94: $739-744$

26. Fraser R, Horowitz M, Graham S, Dent J (1989) Acute hyperglycaemia and antropyloroduodenal motility in humans. Gastroenterology 96: A157 (Abstract)

27. Fox S, Behar J (1980) Pathogenesis of diabetic gastroparesis - a pharmacologic study. Gastroenterology 78: 757-763

28. Oliviera RB, Troncon LEA, Meneghelli UG, Dantas RO, Godoy RA (1984) Gastric accommodation to distention and early gastric emptying in diabetes with neuropathy. Braz J Med Biol Res 17: 49-55

29. Feldman M, Smith HJ, Simon TR (1984) Gastric emptying of solid radiopaque markers: studies in healthy subjects and diabetic patients. Gastroenterology 87: 895 902

30. Hirano T, Niijima A (1980) Effects of 2-deoxy-d-glucose, glucose and insulin on efferent activity in gastric vagues nerve. Experientia 36: 1197-1205

31. Pfeifer MA, Weinberg CR, Cook DL, Reenan A, Halter JB, Ensinck JW, Porte D (1984) Autonomic neural function in recently diagnosed diabetic subjects. Diabetes Care 7: 447-453
32. Hilsted J (1982) Pathophysiology in diabetic autonomic neuropathy: cardiovascular, hormonal, and metabolic studies. Diabetes 31: 730-737

33. Phaosawasdi K, Goppold R, Fisher RS (1981) Pyloric pressure response to insulin-induced hypoglycaemia in humans. Am J Physiol 241: G321-327

34. Schade RR, Dugas MC, Lhotsky DM, Gavaler JS, Van Thiel DH van (1985) Effect of metoclopramide on gastric liquid emptying in patients with diabetic gastroparesis. Dig Dis Sci 30: 10-15

35. Groop LC, Luzi L, DeFronzo R, Melander A (1989) Hyperglycaemia and absorption of sulphonylurea drugs. Lancet II: $129-130$

Received: 15 January 1990

and in revised form: 29 May 1990

Dr M.Horowitz

Department of Medicine

Royal Adelaide Hospital

North Terrace

Adelaide, 5000, South Australia 